\title{
Brucella microti sp. nov., isolated from the common vole Microtus arvalis
}

Holger C. Scholz, ${ }^{1}$ Zdenek Hubalek, ${ }^{2}$ Ivo Sedláček, ${ }^{3}$ Gilles Vergnaud, ${ }^{4,5}$ Herbert Tomaso, ${ }^{1}$ Sascha Al Dahouk, ${ }^{1} \dagger$ Falk Melzer, ${ }^{6}$ Peter Kämpfer, ${ }^{7}$ Heinrich Neubauer, ${ }^{6}$ Axel Cloeckaert, ${ }^{8}$ Marianne Maquart, ${ }^{8}$ Michel S. Zygmunt, ${ }^{8}$ Adrian M. Whatmore, ${ }^{9}$ Enevold Falsen, ${ }^{10}$ Peter Bahn, ${ }^{11}$ Cornelia Göllner, ${ }^{11}$ Martin Pfeffer, ${ }^{1}$ Birgit Huber, ${ }^{12}$ Hans-Jürgen Busse ${ }^{12}$ and Karsten Nöckler ${ }^{11}$

Correspondence Holger C. Scholz Holger1Scholz@bundeswehr.org

\footnotetext{
${ }^{1}$ Bundeswehr Institute of Microbiology, Neuherbergstrasse 11, D-80937 Munich, Germany ${ }^{2}$ Institute of Vertebrate Biology, Academy of Sciences, Kvetna 8, CZ-60365 Brno, Czech Republic ${ }^{3}$ Czech Collection of Microorganisms, Faculty of Science, Masaryk University, Brno, Czech Republic

${ }^{4}$ Centre d'Etudes du Bouchet, BP3, 91710 Vert le Petit, France

${ }^{5}$ Université Paris-Sud, Institut de Génétique et Microbiologie, Orsay, F-91405, France; CNRS, Orsay F-91405, France

${ }^{6}$ Friedrich Loeffler Institute, Institute of Bacterial Infections and Zoonoses, German Reference Center for Brucellosis, Jena, Germany

${ }^{7}$ Institute for Applied Microbiology, Justus-Liebig-Universität Giessen, IFZ, Heinrich-Buff- Ring 26-32, D-35392 Giessen, Germany

${ }^{8}$ INRA, UR1282, Infectiologie Animale et Santé Publique, IASP, Nouzilly, F-37380, France

${ }^{9}$ Veterinary Laboratories Agency, Woodham Lane, Addlestone KT15 3NB, UK

${ }^{10}$ Culture Collection, Department of Clinical Bacteriology, University of Göteborg, Guldhedsg. 10 S-41346 Göteborg, Sweden

${ }^{11}$ Federal Institute for Risk Assessment, Diedersdorfer Weg 1, D-12277 Berlin, Germany

${ }^{12}$ Institut für Bakteriologie, Mykologie und Hygiene, Veterinärmedizinische Universität, A-1210 Wien, Austria
}

Two Gram-negative, non-motile, non-spore-forming, coccoid bacteria (strains CCM $4915^{\top}$ and CCM 4916), isolated from clinical specimens of the common vole Microtus arvalis during an epizootic in the Czech Republic in 2001, were subjected to a polyphasic taxonomic study. On the basis of 16S rRNA ( $r r s$ ) and recA gene sequence similarities, both isolates were allocated to the genus Brucella. Affiliation to Brucella was confirmed by DNA-DNA hybridization studies. Both strains reacted equally with Brucella M-monospecific antiserum and were lysed by the bacteriophages $\mathrm{Tb}, \mathrm{Wb}, \mathrm{F} 1$ and F25. Biochemical profiling revealed a high degree of enzyme activity and metabolic capabilities not observed in other Brucella species. The omp2a and omp $2 b$ genes of isolates CCM $4915^{\top}$ and CCM 4916 were indistinguishable. Whereas omp2a was identical to omp $2 a$ of brucellae from certain pinniped marine mammals, omp $2 b$ clustered with omp $2 b$ of terrestrial brucellae. Analysis of the $b p 26$ gene downstream region identified strains CCM $4915^{\top}$ and CCM 4916 as Brucella of terrestrial origin. Both strains harboured five to six copies of the insertion element IS711, displaying a unique banding pattern as determined by Southern blotting. In comparative multilocus VNTR (variable-number tandem-repeat) analysis (MLVA) with 296 different genotypes, the two isolates grouped together, but formed a separate

tPresent address: RWTH University of Aachen, Department of Internal Medicine III, Pauwelsstraße 30, D-52074 Aachen, Germany.

Abbreviations: MLST, multilocus sequence typing; MLVA, multilocus VNTR (variable-number tandem-repeat) analysis; RTD, routine test dilution. The GenBank/EMBL/DDBJ accession numbers for the gene sequences omp22, omp25, omp25b, omp31 and omp31b of strain CCM $4915^{\top}$ are AM712379, AM712381, AM712383, AM712385 and AM712387, respectively. 
cluster within the genus Brucella. Multilocus sequence typing (MLST) analysis using nine different loci also placed the two isolates separately from other brucellae. In the IS711-based AMOS PCR, a 1900 bp fragment was generated with the Brucella ovis-specific primers, revealing that the insertion element had integrated between a putative membrane protein and $c b o L$, encoding a methyltransferase, an integration site not observed in other brucellae. Isolates CCM $4915^{\top}$ and CCM 4916 could be clearly distinguished from all known Brucella species and their biovars by means of both their phenotypic and molecular properties, and therefore represent a novel species within the genus Brucella, for which the name Brucella microti sp. nov. with the type strain CCM $4915^{\top}\left(=\right.$ BCCN $07-01^{\top}=$ CAPM $\left.6434^{\top}\right)$ is proposed.

At the time of writing, the genus Brucella comprises the six species Brucella melitensis, Brucella abortus, Brucella suis, Brucella canis, Brucella neotomae and Brucella ovis (Corbel \& Brinley-Morgan, 1984). Two potential novel species of marine mammal origin, Brucella pinnipedialis (formerly 'Brucella pinnipediae') and Brucella ceti (formerly 'Brucella cetaceae'), have been proposed recently (Cloeckaert et al., 2001; Foster et al., 2007). Due to the high DNA-DNA relatedness of $>90 \%$ among these species, it was suggested that the genus should comprise only one species, $B$. melitensis, with the six biovars Melitensis, Abortus, Canis, Neotomae, Ovis and Suis (Verger et al., 1985). However, in 2003, the ICSP Subcommittee on the Taxonomy of Brucella agreed unanimously on a return to pre-1986 Brucella taxonomy and as a consequence to the reapproval of the six Brucella species with the recognized biovars (Osterman \& Moriyón, 2006).

Historically, classification of Brucella species was based on natural host preference (main isolation source) and phenotypic characteristics, i.e. $\mathrm{CO}_{2}$ requirement, $\mathrm{H}_{2} \mathrm{~S}$ production, dye-sensitivity, oxidative metabolic profiles, lysis by Brucella-specific bacteriophages and agglutination with monospecific antisera. Indeed, the last proposal for minimal standards to describe novel Brucella species was made by Corbel \& Brinley-Morgan (1975) and certainly has to be reviewed, in respect of the newly developed molecular typing techniques and evolutionary findings.

Because of the high DNA-DNA relatedness and phenotypic similarity among the different Brucella species, a battery of phenotypic and genotypic tests is required for species delineation and for characterization of potentially novel Brucella species. Natural host preference might be used as a further criterion if enough isolates are available.

Recently, molecular approaches, in particular analysis of DNA polymorphism of outer-membrane genes (Cloeckaert et al., 1995, 2001; Vizcaíno et al., 2004), a set of speciesdifferentiating PCR (PCR-restriction fragment length polymorphism; PCR-RFLP) assays (Al Dahouk et al., 2005; Garcia-Yoldi et al., 2006; Ferrao-Beck et al., 2006; Ratushna et al., 2006), multilocus sequence typing (MLST) (Whatmore et al., 2007) and multilocus VNTR (variablenumber tandem-repeat) analysis (MLVA) typing assays (Le Flèche et al., 2006; Whatmore et al., 2006; Garcia-Yoldi et al., 2007; Al Dahouk et al., 2007) have been developed that allow differentiation of Brucella species and to some extent also at the biovar/biotype level.

Here we describe the classification of two strains, CCM $4915^{\mathrm{T}}$ and CCM 4916, which had been originally isolated on meat peptone agar (MPA) at $37^{\circ} \mathrm{C}$ under aerobic conditions from clinical specimens of diseased wild common voles (Microtus arvalis) during a recent epizootic in the Břeclav district in South Moravia, Czech Republic (Hubalek et al., 2007), as a novel species of the genus Brucella.

The phenotype of strains CCM $4915^{\mathrm{T}}$ and CCM 4916 was investigated according to growth behaviour on different media, $\mathrm{CO}_{2}$ requirement, $\mathrm{H}_{2} \mathrm{~S}$ production, growth in the presence of dyes (thionine and basic fuchsin), reaction with monospecific $\mathrm{A}$ and $\mathrm{M}$ antisera, bacteriophage typing (Alton et al., 1988) and light and transmission electron microscopy. Metabolic activity in comparison with other Brucella species, Ochrobactrum anthropi LMG $3331^{\mathrm{T}}$ and Ochrobactrum intermedium LMG $3301^{\mathrm{T}}$ was assessed using the Merlin MICRONAUT system (Neubauer et al., 2000). Polar lipids and quinone system were analysed as described by Tindall (1990a, b), Altenburger et al. (1996) and Stolz et al. (2007), and the polyamine pattern was analysed as described by Busse \& Auling (1988) and Stolz et al. (2007), despite the fact that the biomass was not collected from liquid culture but cells were harvested from trypticase soy agar (TSA) and inactivated by acetone.

Molecular analyses comprised AMOS PCR (Bricker \& Halling, 1994), multiplex PCR (Garcia-Yoldi et al., 2006), sequence analysis of the outer membrane genes omp2a, omp2b (Cloeckaert et al., 1995, 2001), omp22, omp25, omp25b, omp31 and omp31b (Vizcaíno et al., 2004), analysis of the $b p 26$ gene downstream region to distinguish between brucellae of marine mammal and terrestrial mammal origin (Cloeckaert et al., 2000), IS711 (IS6501)typing by Southern blotting analysis (Clavareau et al., 1998), MLVA (Le Flèche et al., 2006; Whatmore et al., 2006; Garcia-Yoldi et al., 2007; Al Dahouk et al., 2007), MLST (Whatmore et al., 2007) and DNA-DNA hybridization studies (Ziemke et al., 1998).

Both isolates grew well at 28 and $37{ }^{\circ} \mathrm{C}$ on MPA without supplementary $\mathrm{CO}_{2}$, forming transparent to whitish 
Table 1. Differentiating physiological reactions of B. microti sp. nov. in comparison with other Brucella and Ochrobactrum species.

Taxa: 1, B. microti CCM 4915 ${ }^{\mathrm{T}}$; 2, B. microti CCM 4916; 3, B. abortus strains: $544^{\mathrm{T}}$ (=NCTC 10093 ${ }^{\mathrm{T}}$ ) (bv. 1), 86/8/59 (=NCTC 10501) (bv. 2), Tulya (=NCTC 10502) (bv. 3), 292 (=NCTC 10503) (bv. 4), B3196 (=NCTC 10504) (bv. 5), 870 (=NCTC 10505) (bv. 6), 63175 (=NCTC 10506) (bv. 7), C68 (=NCTC 10507) (bv. 9); 4, B. melitensis strains: $16 \mathrm{M}^{\mathrm{T}}$ (=NCTC 10094 ${ }^{\mathrm{T}}$ ) (bv. 1), 63/9 (=NCTC 10508) (bv. 2), Ether (=NCTC 10509) (bv. 3); 5, B . suis strains: 1330 (=NCTC 10316) (bv. 1), Thomsen (=NCTC 10510) (bv. 2), 686 (=NCTC 10511) (bv. 3), Reference 40 (bv. 4), Reference 513 (bv. 5); 6, B. ovis strain: $63 / 290^{\mathrm{T}}$ (=NCTC $\left.10512^{\mathrm{T}}\right) ; 7$, B. canis strain: RM6/66 ${ }^{\mathrm{T}}\left(=\mathrm{NCTC}_{10854^{\mathrm{T}}}\right)$; 8, B. neotomae strain: $5 \mathrm{~K} 33^{\mathrm{T}}$ $\left(=\right.$ NCTC $\left.10084^{\mathrm{T}}\right) ; 9$, B. pinnipedialis NCTC $12890^{\mathrm{T}} ; 10$, B. ceti NCTC $12891^{\mathrm{T}} ; 11$, O. anthropi LMG $3331^{\mathrm{T}} ; 12$, O. intermedium $\mathrm{LMG} 3301^{\mathrm{T}}$. oNP, onitrophenyl; pNP, $p$-nitrophenyl; +, positive $\left(\mathrm{QO}_{2} \mathrm{~N}\right.$ values $\left.>70\right)$; - , negative $\left(\mathrm{QO}_{2} \mathrm{~N}\right.$ values $\left.<50\right)$; v, variable $\left(\mathrm{QO}_{2} \mathrm{~N}\right.$ values $>50$ and $\left.<70\right)$.

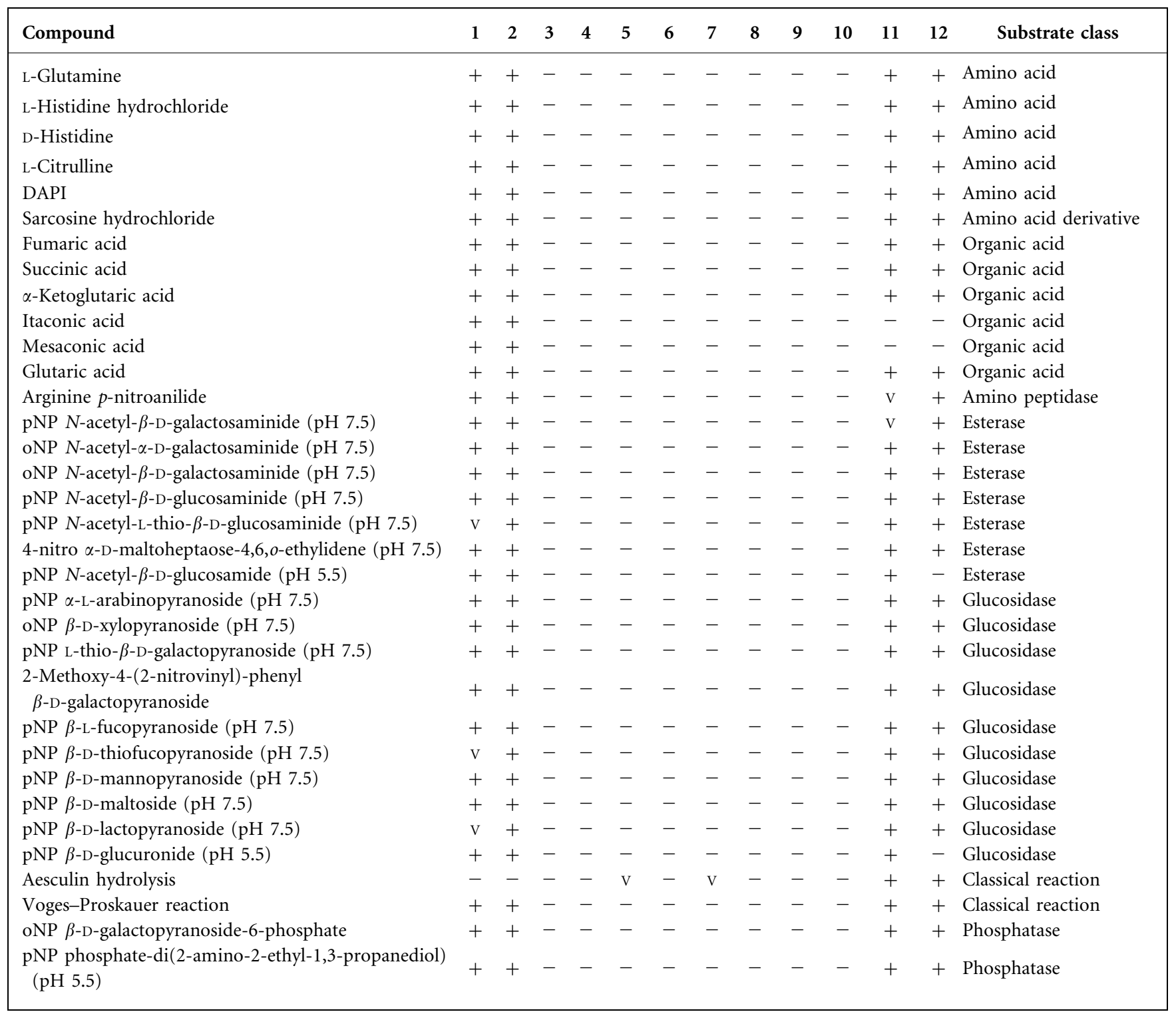

colonies, 1-2 $\mathrm{mm}$ in diameter, after 1-2 days of incubation. $\mathrm{H}_{2} \mathrm{~S}$ was not produced. Good growth was also observed on blood agar and on standard nutrient agar at 28 and $37{ }^{\circ} \mathrm{C}$. Colonies were slightly concave, smooth, with very light brown exopigment; their edges were continuous. After $72 \mathrm{~h}$ of growth at $37{ }^{\circ} \mathrm{C}$, cells appeared as large colonies $(6-9 \mathrm{~mm})$ with noticeable brownish pigmentation. Cell morphology was examined using a Zeiss light microscope at $\times 1000$ magnification with cells grown for 2 days at $37{ }^{\circ} \mathrm{C}$ on standard nutrient agar. Gram staining was performed as described by Gerhardt et al. (1994) with cells grown for 2 days at $28{ }^{\circ} \mathrm{C}$ on MPA. Cells were small $(<1 \mu \mathrm{m})$ Gramnegative coccobacilli or sporadically formed short rods, arranged individually or in irregular clusters. Flagellation 


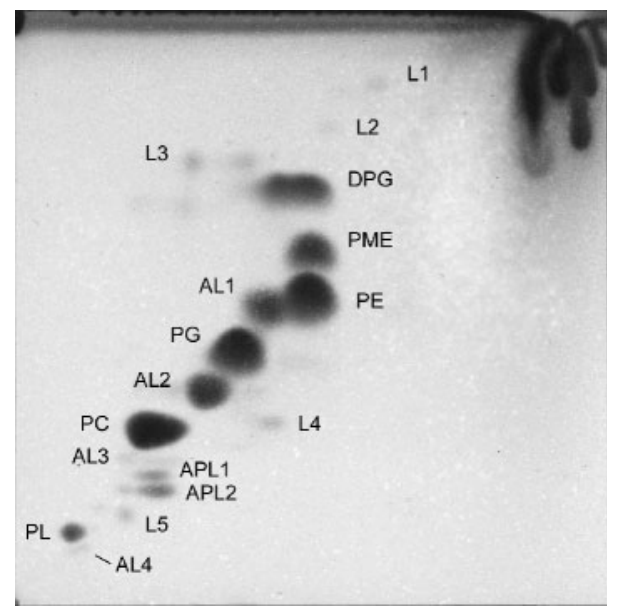

Fig. 1. Two-dimensional thin-layer chromatogram of total polar lipids of strain CCM $4915^{\top}$. PME, Phosphatidylmonomethylethanolamine; $\mathrm{PE}$, phosphatidylethanolamine; $\mathrm{PC}$, phosphatidylcholine; DPG, diphosphatidylglycerol; PG, phosphatidylglycerol; AL1-4, unknown aminolipids; PL, unknown phospholipid; APL1 and 2, unknown aminophospholipids; L1-5, unknown polar lipids.

was determined by transmission electron microscopy (negative staining with $1 \%$ uranyl acetate) using a JEM1010 electron microscope at a magnification of $\times 40000$. Cells were unflagellated and morphologically indistinguishable from B. melitensis $16 \mathrm{M}^{\mathrm{T}}$, whereas flagella were clearly visible on O. anthropi LMG $3331^{\mathrm{T}}$ (data not shown), which is the type species of the phylogenetically closest genus.

Besides the classical biochemical reactions (Hubalek et al., 2007), a total of 191 different carbohydrates, 190 substrates to determine enzymic activity and 191 different substrates for use as a nitrogen source were tested by using the Merlin MICRONAUT identification system (Neubauer et al., 2000). Each reaction was carried out seven times. The results of the differentiating biochemical reactions of strains CCM $4915^{\mathrm{T}}$ and CCM 4916 in comparison with the other Brucella species and their biovars as well as with Ochrobactrum species are summarized in Table 1. The results demonstrate that both isolates exhibit outstanding metabolic capabilities with respect to all other brucellae, sharing a series of reactions with O. anthropi LMG $3331^{\mathrm{T}}$ and O. intermedium LMG $3301^{\mathrm{T}}$. It is remarkable that both strains were positive in the Voges-Proskauer reaction. Additional results of the phenotypic characterization of strains CCM $4915^{\mathrm{T}}$ and CCM 4916 by classical methods are given in the species description.

The two strains exhibited a quinone system with ubiquinone Q-10 (91-97\%) and Q-9 (3-9\%). A similar quinone system was detected in B. melitensis, with Q-10 (97\%) and Q-9 (3\%). Their polar lipid profiles consisted of the major compounds phosphatidylethanolamine, phosphatidylmonomethylethanolamine, phosphatidylglycerol, diphosphatidylglycerol, phosphatidylcholine and two unknown aminolipids (AL1 and 2), moderate amounts of an unknown phospholipid PL and small to trace amounts of additional unknown aminolipids (AL3 and 4), two unknown aminophospholipids (APL1 and 2) and five unknown polar lipids (Fig. 1). Two additional lipids, one staining positively with ninhydrin (aminolipid) and the other with molybdenum blue (phospholipid), may be present, showing almost the same chromatographic behaviour as AL1, but their presence could not unambiguously confirmed because of insufficient resolution from AL1 in the thin-layer chromatography. B. abortus NCTC $10093^{\mathrm{T}}$ and B. melitensis $16 \mathrm{M}^{\mathrm{T}}$ exhibited almost the same profile (results not shown), but unknown aminolipid AL2 was not detectable in these two strains and phosphatidylmonomethylethanolamine was present either in traces or lacking. The polyamine patterns of strains CCM $4915^{\mathrm{T}}$ and CCM 4916 contained the major compound spermidine (77.0$80.2 \%)$, putrescine (14.0-16.8\%), 1,3-diaminopropane (3.4-5.0\%), sym-homospermidine $(0.8-1.9 \%)$ and spermine $(0.4-0.5 \%)$. Similar polyamine patterns were detected in B. melitensis $16 \mathrm{M}^{\mathrm{T}}$ ( $74.2 \%$ spermidine, $18.6 \%$ putrescine, $3.0 \%$ 1,3-diaminopropane, $3.5 \%$ sym-homospermidine and $0.4 \%$ spermine) and representative species of the genus Ochrobactrum, including O. intermedium LMG $3301^{\mathrm{T}}$ (results not shown), the nearest phylogenetic relative of the genus Brucella. In contrast, species of the genus Pseudochrobactrum exhibit a polyamine pattern lacking symhomospermidine (Kämpfer et al., 2006, 2007).

In the IS711-based AMOS multiplex-PCR, a 1900 bp fragment, not amplified from other Brucella species, was generated. Using single species-specific primer pairs, it could be demonstrated that the fragment was amplified with the B. ovis-specific primers (Hubalek et al., 2007). Sequencing of the PCR product and subsequent comparative BLASTN analyses revealed that the IS element has integrated between the coding sequences of a putative membrane protein (TIGR/KEGG locus tag BR1284/ BMEI0717) and $c b o L$ (BR1285/BME0716), a methyltransferase gene (data not shown). At the B. ovis primer side the partial radC (BR1283/BMEI0718) gene, involved in DNA repair, is present. In none of the published Brucella genomes is IS711 located at this position. In the multiplex PCR developed by Garcia-Yoldi et al. (2006), strains CCM $4915^{\mathrm{T}}$ and CCM 4916 were indistinguishable from B. suis (data not shown).

The entire open reading frames of the omp22 (639 bp), omp25 (642 bp) and omp31 (752 bp) genes were identical to the corresponding genes of Brucella suis 1330 (GenBank accession no. AE014291.4), Brucella ceti B202R (AY484523.1) and Brucella pinnipedialis B2/94 ${ }^{\mathrm{T}}$ (AY484522.1). Similarity values of $99 \%$ (one to three substitutions) were observed with other brucellae. Within omp31b (786 bp), neither deletions, as reported for $B$. melitensis, nor premature stop codons, as observed for $B$. canis and B. ovis (Vizcaíno et al., 2004), nor inversion of the omp25b gene ( $785 \mathrm{bp})$, as described for the majority of B. ceti strains (Vizcaíno et al., 2004), were detected. 


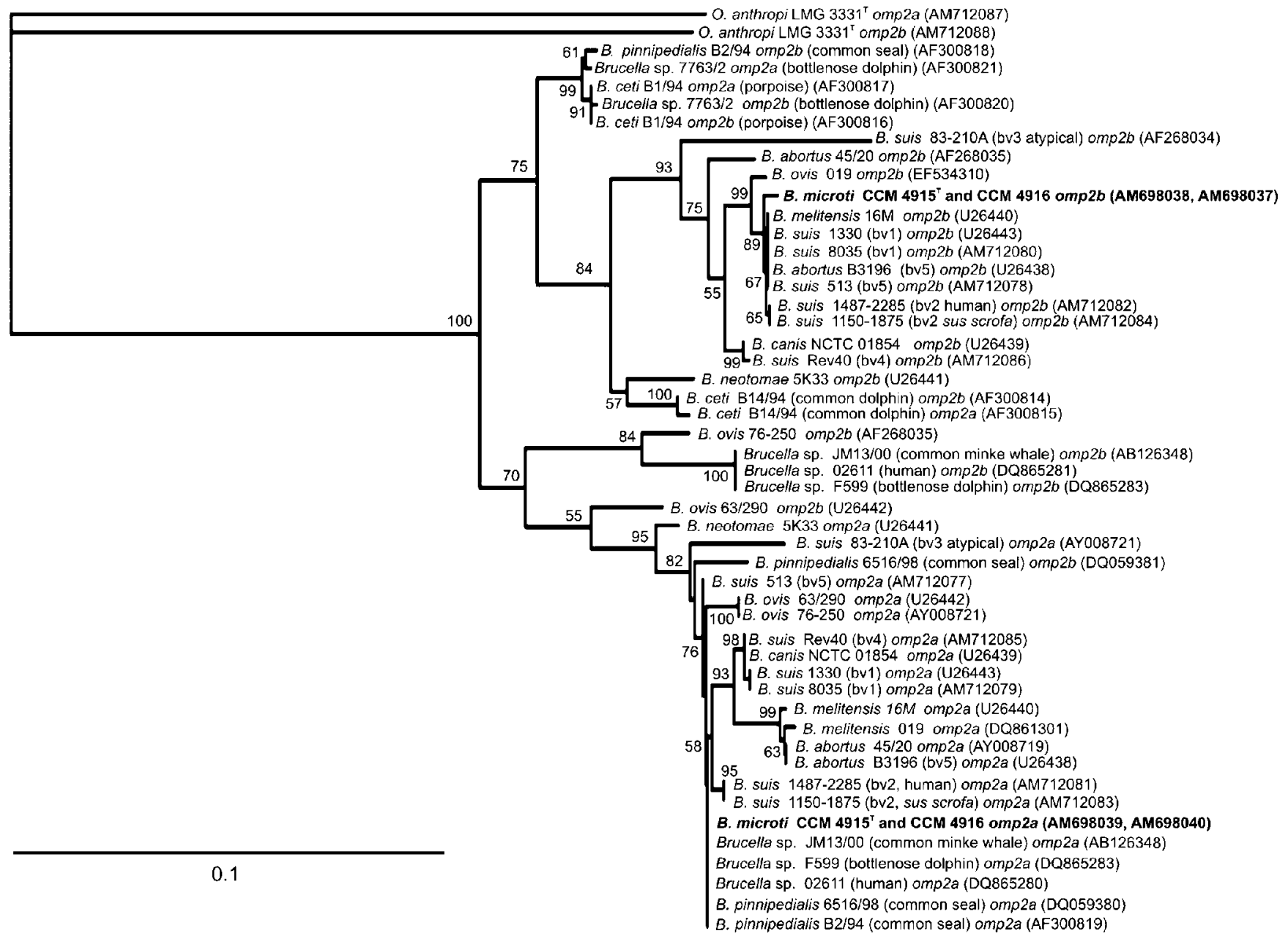

Fig. 2. Phylogenetic tree reconstructed with omp2a (1104 nt) and omp $2 b(1089 \mathrm{nt})$ sequences using CLUSTREE neighbourjoining analysis. The significance of each branch is indicated by a bootstrap percentage calculated for 1000 subsets. The tree was rooted by outgrouping sequence omp2a of $O$. anthropi LMG $3331^{\top}$. Bar, 0.1 divergent residues per site.

The omp $2 a$ genes were $100 \%$ identical to omp $2 a$ of the marine Brucella pinnipedialis strain B2/94 ${ }^{\mathrm{T}}$ (GenBank accession no. AF300819) and some other Brucella strains isolated from marine mammals, i.e. Brucella pinnipedialis strain 6516/9 (DQ059380) and Brucella sp. JM13/00 (AB126348). In contrast, the omp2b genes were mostly related to omp $2 b$ of Brucella strains from terrestrial mammals with one to three mismatches, (99-98\% similarity). The combination of omp $2 a$ from marine mammal and omp $2 b$ from terrestrial mammal origin has not yet been described.

A phylogenetic neighbour-joining tree constructed with omp $2 a$ and $o m p 2 b$ of strains CCM $4915^{\mathrm{T}}$ and CCM 4916, B. suis biovars (bv) 2, 4, 5 and sequences available from the EMBL nucleotide database is shown in Fig. 2. The tree was constructed using the online accessible bioinformatics tools of HUSAR, available from http://genius.embnet.dkfzheidelberg.de/menu/w2h/w2hdkfz. It was constructed from the alignments obtained with CLUSTREE and the implemented Kimura two-parameter model. In order to assess probabilities of the nodes, 1000 bootstrap resamplings were performed. The tree was rooted with omp $2 a$ of Ochrobactrum anthropi LMG $3331^{\mathrm{T}}$ as the outgroup.

The PCR fragment size of the $b p 26$ gene downstream region was $1029 \mathrm{bp}$, which is characteristic for terrestrial mammal brucellae (data not shown).

The MLVA data obtained with strains CCM $4915^{\mathrm{T}}$ and CCM 4916 were compared with 424 Brucella isolates corresponding to 296 genotypes that have previously been analysed by Le Flèche et al. (2006), Garcia-Yoldi et al. (2007) and Al Dahouk et al. (2007). Cluster analysis was performed as described by Al Dahouk et al. (2007) using eight-minisatellite (panel 1) and seven-microsatellite VNTR markers (panel 2) and the categorical distance coefficient and the unweighted pair-group method using arithmetic averages (UPGMA) clustering method. Briefly, the seven microsatellites are divided in two groups, taking 
into account their mutation rate (Garcia-Yoldi et al., 2007). Panel 2A comprises the most stable microsatellites Bruce 18, 19, 21 and 30. Panel 2B comprises the highly variable markers Bruce 07, 09 and 16. In the clustering analysis, markers from panel $1,2 \mathrm{~A}$ and $2 \mathrm{~B}$ were given an individual weight of respectively 2,1 and 0.3 . In this analysis, the two strains clustered together (and differed from each other by 4 out of 16 VNTR loci, including one marker from panel $2 \mathrm{~A}$ and the three markers from panel $2 \mathrm{~B}$ ), but grouped separately from all other known Brucella species and their biovars (Fig. 3). Because of the large number of strains, clusters were condensed. $B$. neotomae reference strain $5 \mathrm{~K} 33$ and B. pinnipedialis strain B2/94 appear as closest neighbours in this analysis, whereas the two $B$. suis biovar 5 strains are more distantly related.

In MLST analysis (Whatmore et al., 2007), the two strains clustered separately from other Brucella strains most closely related to B. suis biovar 5 (ST19) and marine mammal ST25, from which they differ at two out of nine loci (Fig. 4). The MLST profile was 1-11-4-2-1-3-5-2-1. In the IS711 insertion element typing analysis using the Southern blotting technique, the two isolates were indistinguishable from each other, but exhibited a unique banding pattern when compared with other Brucella species, corresponding to five to six copies (not shown).

Results from DNA-DNA hybridizations using labelled DNA of B. melitensis $16 \mathrm{M}^{\mathrm{T}}$ showed $84.1 \% \pm 0.7$ DNA relatedness with strain CCM $4915^{\mathrm{T}}$. These results are in agreement with previous reports (Verger et al., 1985) which showed that, if the $70 \%$ DNA-relatedness threshold value is applied, species of this genus cannot be separated based on results from DNA-DNA hybridizations. The DNA relatedness to the phylogenetically closest neighbour, $O$. intermedium LMG $3301^{\mathrm{T}}$, was $55.5 \%$.

In summary, from the results of the phenotypic and genotypic analyses, it is evident that isolates CCM $4915^{\mathrm{T}}$ and CCM 4916 are members of the genus Brucella, but can be clearly differentiated from all established species of this genus, including their biovars. Hence, by applying the Brucella species concept suggested by the ICSP Subcommittee on the taxonomy of Brucella (Osterman \& Moriyón, 2006), the two strains represent a novel species of the genus Brucella, for which we propose the name Brucella microti sp. nov.

Future investigations such as whole-genome sequencing and studies on host cell interactions will provide further insight in the evolution of brucellae and host-pathogen interactions.

\section{Description of Brucella microti sp. nov.}

Brucella microti (mi.cro'ti. L. gen. n. microti of Microtus, after the vole genus from which the first strains of this species have been isolated).

Cocci, coccobacilli or short rods, $0.5-0.8 \mu \mathrm{m}$ in diameter and $0.6-1.4 \mu \mathrm{m}$ in length. Arranged individually or in

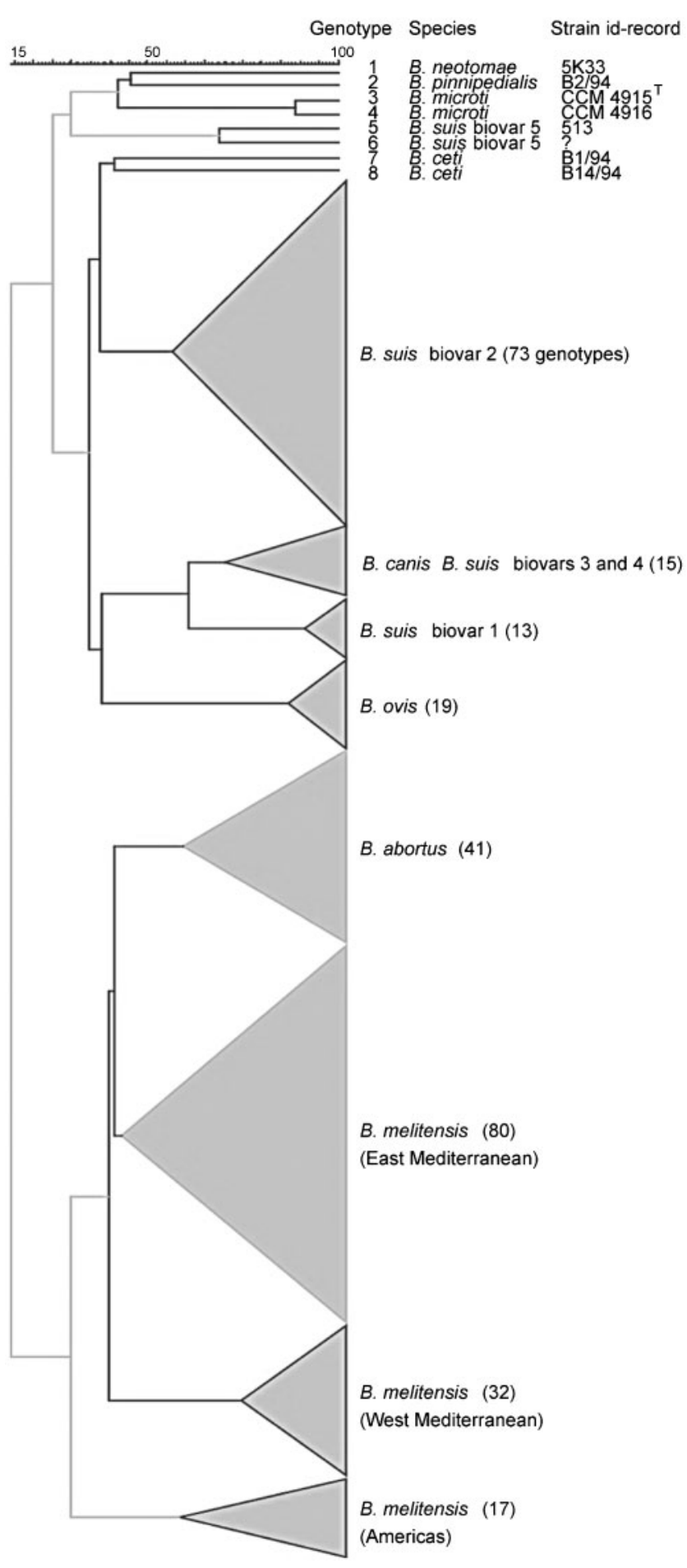

Fig. 3. Condensed dendrogram of clustered MLVA-16 genotypes obtained with 424 Brucella isolates corresponding to 296 different genotypes. Bar, percentage of sequence divergence.

irregular clusters. Gram-negative. Aerobic, non-fermentative, non-motile, non-spore-forming. Oxidase-, catalaseand urease-positive. Nitrate and nitrite are reduced (with gas formation from nitrate). No production of $\mathrm{H}_{2} \mathrm{~S}$, 


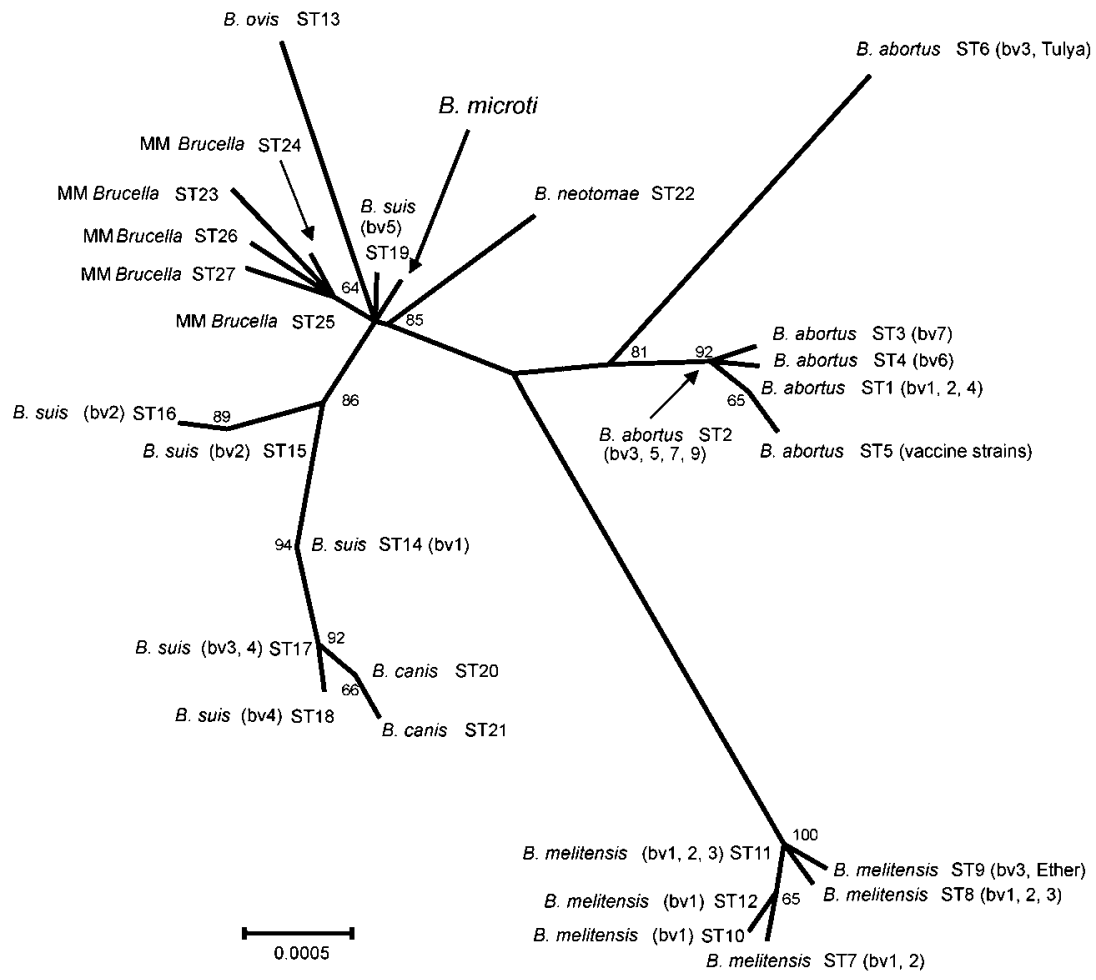

Fig. 4. Unrooted phylogenetic reconstruction of the relationships between sequence types (ST). This tree was constructed with the concatenated sequence data of the nine loci (4396 bp) using the neighbour-joining approach. The Jukes-Cantor model, which is based on the assumption that all nucleotide substitutions are equally likely, was used to determine genetic distances. Percentage bootstrap confidence levels of internal branches were calculated from 1000 resamplings of the original data. bv, Biovar; MM, marine mammals. Bar, 0.0005 substitutions per site.

arginine dihydrolase, lysine decarboxylase, ornithine decarboxylase, fluorescein (King's B medium). Negative on Simmons' citrate, malonate and acetamide and no growth in broth with $6.5 \% \mathrm{NaCl}$. Positive (API 20NE) for Dglucose, maltose, L-arabinose, D-mannose, $\mathrm{N}$-acetylglucosamine and adipic acid. Negative for D-mannitol, citric acid, gluconate, capric acid, malic acid and phenylacetic acid. Acid is produced from glucose, maltose, fructose and xylose in OF medium (Difco). Positive (API ZYM) for acid phosphatase, alkaline phosphatase, leucine arylamidase, valine arylamidase, cystine arylamidase, $\beta$-glucosidase and esterase lipase. Enzymes absent on API ZYM are esterase, lipase, $\alpha$ - and $\beta$-galactosidase, $\beta$-glucosidase, $\beta$-glucuronidase, $N$-acetyl- $\beta$-glucosaminidase, $\alpha$-mannosidase and $\alpha$ fucosidase. Starch, casein, DNA, tyrosine, aesculin, ONPG, Tween 80, lecithin and gelatin are not hydrolysed. Differentiating physiological reactions (MICRONAUT) of strains CCM $4915^{\mathrm{T}}$ and CCM 4916 with respect to other Brucella species and biovars and Ochrobactrum anthropi LMG $3331^{\mathrm{T}}$ are given in Table 1. Cells are sensitive to gentamicin, tobramycin, cotrimoxazole (trimethoprim plus sulphamethoxazole) and ofloxacin, but resistant to colistin, piperacillin, ceftazidime and tazobactam. Nonfastidious; good growth occurs on MPA, TSA, blood agar and standard nutrient agar at $25-42{ }^{\circ} \mathrm{C}$. Beige, translucent to whitish colonies with light-brown exopigment and entire edges are formed within $24 \mathrm{~h}$, with a diameter of approximately $2 \mathrm{~mm}$. Good growth does not require $\mathrm{CO}_{2}$, supplementary serum or blood. No haemolysis is observed. Isolates grow with thionine at dilutions of $1 / 25000,1 /$ 50000 and 1/100 000, and with basic fuchsin at dilutions of
1/50 000 and 1/100 000. Cultures are lysed by Tb, F1 and F25 phages at routine test dilution (RTD) $10^{4}$ but not at RTD and by Weybridge phage ( $\mathrm{Wb}$ ) at both dilutions. Both strains agglutinate with monospecific anti-M serum up to a dilution of $1: 80$. The quinone system is composed of the major compound ubiquinone Q-10 and minor amounts of Q-9. Predominant polar lipids are phosphatidylethanolamine, phosphatidylmonomethylethanolamine, phosphatidylglycerol, diphosphatidylglycerol, phosphatidylcholine and two unknown aminolipids, moderate amounts of an unknown phospholipid PL and small to trace amounts of additional unknown aminolipids (AL3 and 4), two unknown aminophospholipids (APL1 and 2) and five unknown polar lipids. The polyamine pattern contains the major compound spermidine, moderate amounts of putrescine and small amounts of 1,3-diaminopropane, symhomospermidine and spermine.

The type strain is CCM $4915^{\mathrm{T}}\left(=\mathrm{BCCN} 07-01^{\mathrm{T}}=\mathrm{CAPM}\right.$ $6434^{\mathrm{T}}$ ) isolated in 2000 from the liver of Microtus arvalis, South Moravia, Czech Republic. Another strain of this species is CCM 4916.

\section{Acknowledgements}

We are grateful to Csilla Lodri, Stefan Schatz and Angelika Draeger for excellent technical assistance. We thank Philippe Le Flèche for the MLVA typing and Mark S. Koylass for MLST analysis of strains CCM $4915^{\mathrm{T}}$ and CCM 4916. The development of genotyping methods for the precise strain identification of dangerous pathogens as part of microbial forensics is supported by the French DGA (Délégation Générale pour l'Armement). The work of B.H. and H.-J. B. was 
supported by a Contract-Research-Project for the Bundeswehr Medical Service.

\section{References}

Al Dahouk, S., Tomaso, H., Prenger-Berninghoff, E., Splettstoesser, W. D., Scholz, H. C. \& Neubauer, H. (2005). Identification of Brucella species and biotypes using polymerase chain reaction-restriction fragment length polymorphism (PCR-RFLP). Crit Rev Microbiol 31, 191-196.

Al Dahouk, S., Le Flèche, P., Noeckler, K., Jacques, I., Grayon, M., Scholz, H. C., Tomaso, H., Vergnaud, G. \& Neubauer, H. (2007). Evaluation of Brucella MLVA typing for human brucellosis. J Microbiol Methods 69, 137-145.

Altenburger, P., Kämpfer, P., Makristathis, A., Lubitz, W. \& Busse, H.-J. (1996). Classification of bacteria isolated from a medieval wall painting. J Biotechnol 47, 39-52.

Alton, G. G., Jones, L. M., Angus, R. D. \& Verger, J. M. (1988). Techniques for the Brucellosis Laboratory (Techniques et Pratiques). Paris: INRA.

Bricker, B. J. \& Halling, S. M. (1994). Differentiation of Brucella abortus bv. 1, 2, and 4, Brucella melitensis, Brucella ovis and Brucella suis bv. 1 by PCR. J Clin Microbiol 32, 2660-2666.

Busse, H. J. \& Auling, G. (1988). Polyamine pattern as a chemotaxonomic marker within the Proteobacteria. Syst Appl Microbiol 11, 1-8.

Clavareau, C., Wellemans, V., Walravens, K., Tryland, M., Verger, J.-M., Grayon, M., Cloeckaert, A., Letesson, J. J. \& Godfroid, J. (1998). Phenotypic and molecular characterization of a Brucella strain isolated from a minke whale (Balaeonoptera acutorostrata). Microbiology 144, 3267-3273.

Cloeckaert, A., Verger, J. M., Grayon, M. \& Grepinet, O. (1995). Restriction site polymorphism of the genes encoding the major 25 $\mathrm{kDa}$ and $36 \mathrm{kDa}$ outer-membrane proteins of Brucella. Microbiology 141, 2111-2121.

Cloeckaert, A., Grayon, M. \& Grepinet, O. (2000). An IS711 element downstream of the bp26 gene is a specific marker of Brucella spp. isolated from marine mammals. Clin Diagn Lab Immunol 7, 835-839.

Cloeckaert, A., Verger, J.-M., Grayon, M., Paquet, J. Y., Garin-Bastuji, B., Foster, G. \& Godfroid, J. (2001). Classification of Brucella spp. isolated from marine mammals by DNA polymorphism at the omp2 locus. Microbes Infect 3, 729-738.

Corbel, M. J. \& Brinley-Morgan, W. J. (1975). Proposal for minimal standards for descriptions of new species and biotypes of the genus Brucella. Int J Syst Bacteriol 25, 83-89.

Corbel, M. J. \& Brinley-Morgan, W. J. (1984). Genus Brucella. In Bergey's Manual of Systematic Bacteriology, vol. 1, pp. 377-388. Edited by N. R. Krieg \& J. G. Holt. Baltimore: Williams \& Wilkins.

Ferrao-Beck, L., Cardoso, R., Munoz, P. M., de Miguel, M. J., Albert, D., Ferreira, A. C., Marin, C. M., Thiebaud, M., Jacques, I. \& other authors (2006). Development of a multiplex PCR assay for polymorphism analysis of Brucella suis biovars causing brucellosis in swine. Vet Microbiol 115, 269-277.

Foster, G., Osterman, B., Godfroid, J., Jacques, I. \& Cloeckaert, A. (2007). Brucella ceti sp. nov. and Brucella pinnipedialis sp. nov. for Brucella strains with cetaceans and seals as their preferred hosts. Int $J$ Syst Evol Microbiol 57, 2688-2693.

Garcia-Yoldi, D., Marin, C. M., de Miguel, M. J., Munoz, P. M., Vizmanos, J. L. \& Lopez-Goni, I. (2006). Multiplex PCR assay for the identification and differentiation of all Brucella species and the vaccine strains Brucella abortus S19 and RB51 and Brucella melitensis Rev1. Clin Chem 52, 779-781.
Garcia-Yoldi, D., Le Flèche, P., Marin, C. M., De Miguel, M. J., Munoz, P. M., Vergnaud, G. \& Lopez-Goni, I. (2007). Assessment of genetic stability of Brucella melitensis Rev 1 vaccine strain by multiple-locus variable-number tandem repeat analysis. Vaccine 25, 2858-2862.

Gerhardt, P., Murray, R. G. E., Wood, W. A. \& Krieg, N. R. (editors) (1994). Methods for General and Molecular Bacteriology. Washington, DC: American Society for Microbiology.

Hubálek, Z., Scholz, H. C., Sedláček, I., Melzer, F., Sanogo, Y. \& Nesvadbová, J. (2007). Brucellosis of the common vole (Microtus arvalis). Vector Borne Zoonotic Dis 7, 679-688.

Kämpfer, P., Rosselló-Mora, R., Scholz, H. C., Welinder-Olsson, C., Falsen, E. \& Busse, H.-J. (2006). Description of Pseudochrobactrum gen. nov., with the two species Pseudochrobactrum asaccharolyticum sp. nov. and Pseudochrobactrum saccharolyticum sp. nov. Int J Syst Evol Microbiol 56, 1823-1829.

Kämpfer, P., Scholz, H., Huber, B., Thummes, K., Busse, H.-J., Maas, E. W. \& Falsen, E. (2007). Description of Pseudochrobactrum kiredjianiae sp. nov. Int J Syst Evol Microbiol 57, 755-760.

Le Flèche, P., Jacques, I., Grayon, M., Al Dahouk, S., Bouchon, P., Denoeud, F., Nockler, K., Neubauer, H., Guilloteau, L. A. \& Vergnaud, G. (2006). Evaluation and selection of tandem repeat loci for a Brucella MLVA typing assay. BMC Microbiol 6, 9.

Neubauer, H., Molitor, M., Rahalison, L., Aleksic, S., Backes, H., Chanteau, S. \& Meyer, H. (2000). A miniaturised semiautomated system for identification of Yersinia species within the genus Yersinia. Clin Lab 46, 561-567.

Osterman, B. \& Moriyón, I. (2006). International Committee on Systematics of Prokaryotes Subcommittee on the Taxonomy of Brucella. Minutes of the meeting, 17 September 2003, Pamplona, Spain. Int J Syst Evol Microbiol 56, 1173-1175.

Ratushna, V. G., Sturgill, D. M., Ramamoorthy, S., Reichow, S. A., He, Y., Lathigra, R., Sriranganathan, N., Halling, S. M., Boyle, S. M. \& other authors (2006). Molecular targets for rapid identification of Brucella spp. BMC Microbiol 6, 13.

Stolz, A., Busse, H.-J. \& Kämpfer, P. (2007). Pseudomonas knackmussii sp. nov. Int J Syst Evol Microbiol 57, 572-576.

Tindall, B. J. (1990a). A comparative study of the lipid composition of Halobacterium saccharovorum from various sources. Syst Appl Microbiol 13, 128-130.

Tindall, B. J. (1990b). Lipid composition of Halobacterium lacusprofundi. FEMS Microbiol Lett 66, 199-202.

Verger, J.-M., Grimont, F., Grimont, P. A. D. \& Grayon, M. (1985). Brucella, a monospecific genus as shown by deoxyribonucleic acid hybridization. Int J Syst Bacteriol 35, 292-295.

Vizcaíno, N., Caro-Hernandez, P., Cloeckaert, A. \& Fernandez-Lago, L. (2004). DNA polymorphism in the omp25/omp31 family of Brucella spp.: identification of a 1.7-kb inversion in Brucella cetaceae and of a $15.1-\mathrm{kb}$ genomic island, absent from Brucella ovis, related to the synthesis of smooth lipopolysaccharide. Microbes Infect 6, 821-834.

Whatmore, A. M., Shankster, S. J., Perrett, L. L., Murphy, T. J., Brew, S. D., Thirlwall, R. E., Cutler, S. J. \& MacMillan, A. P. (2006). Identification and characterization of variable-number tandem-repeat markers for typing of Brucella spp. J Clin Microbiol 44, 1982-1993.

Whatmore, A. M., Perrett, L. L. \& Macmillan, A. P. (2007). Characterisation of the genetic diversity of Brucella by multilocus sequencing. BMC Microbiol 7, 34.

Ziemke, F., Höfle, M. G., Lalucat, J. \& Rosselló-Mora, R. (1998). Reclassification of Shewanella putrefaciens Owen's genomic group II as Shewanella baltica sp. nov. Int J Syst Bacteriol 48, 179-186. 